\title{
Uropatía obstructiva: Valvas uretrales posteriores Presentación de un caso clínico
}

\author{
Martha Patricia Matiz*; Vicente J. Carmona P.**
}

\section{RESUMEN}

La uropatía obstructiva secundaria a valvas de la uretra posterior, tiene una presentación clínica variable y a menudo insidiosa, la obstrucción causada por repliegues de mucosa que obstruyen la uretra origina la patología, ocurre solo en hombres y tiene un amplio espectro de características ecográficas cuyos signos cardinales son dilatación persistente de vejiga y la porción proximal de la uretra con engrosamiento de la pared vesical $(2,10)$.

Esta es la presentación de un caso clínico diagnosticado y manejado en la unidad materno fetal y ultrasonografía del Hospital Militar Central.

PALABRAS CLAVES: Valvas uretrales posteriores, uropatía obstructiva.

\section{SUMMARY}

The uropatia obstructive secondary to valves of the uretra subsequent, has a presentation variable clinic and often wrong, the obstruction caused by doublings of mucous that obstruct the uretra originates the pathology, occurs alone in men and has a wide characteristics spectrum ecograficas whose cardinal signs are persistent bladder expansion and the portion proximal of the uretra with engrosamiento of the wall vesical $(2,10)$.

This is the presentation of a diagnosed clinical case and handled in the fetal motherly unit and ultrasonografia of the Central Military Hospital.

KEY WORDS: Valves subsequent Uretrales, Obstructive Uropatia.

\section{Reporte de un caso clínico}

Paciente de 24 años, casada natural y procedente de Bogotá, quien consulta al servicio de urgencias del Hospital Militar Central con cuadro clínico de 2 días de evolución consistente en dolor abdominal tipo cólico, sin ninguna otra sintomatología asociada.

Antecedentes: M: 12 años, C: 28X5, FUR: 16.04.98, FUP. 9 meses. PF: (-). G4PIC1A2.

Examen Fisico: Paciente en buenas condiciones generales, con signos vitales estables.

Ahdomen: Utero grávido, AU: $15 \mathrm{cms}$, RsIs (+). G. Externos: multípara, cérvix central sin evidencia de secreciones ni salida de líquido a las maniobras de valsalva.

Con Impresión Diagnóstica de dolor abdominal a estudio y embarazo de 18 semanas se realiza ecografía obstétrica que evidencia feto único, vivo, con biometría para 18 semanas, ausencia del líquido amniótico y distensión abdominal importante. Se realizó ecografía de detalle previa cordocentesis para cariotipo y amnioinfusión de

\footnotetext{
* RII Servicio de Ginecología y Obstetricia. Hospital Militar Central. ** Jefe Unidad de Medicina Materno-Fetal y Unidad de Ultrasonografia y Doppler. Servicio de Ginecologia y Obstetricia. Hospital Militar Central.
}

SSN, observando marcada ascitis, dilatación vesical importante con engrosamiento de la pared y dos soluciones de continuidad, dilatación de la uretra proximal y aumento de tamaño e hiperecogenicidad renal bilateral, los ureteres no se evidenciaron excepto en la unión vesicoureteral. El resultado del estudio genético confirmó sexo masculino (46XY) sin ninguna malformación genética asociada.

\section{Diagnóstico ecográfico:}

1. Uropatía Obstructiva, Ruptura vesical y Ascitis Urinaria secundaria:

\section{VALVAS URETRALES POSTERIORES.}

Inició espontáneamente trabajo de parto obteniendo Rn masculino, muerto con marcada distensión abdominal sin otros signos mayores de malformaciones.

El estudio patológico y la histología de los órganos reportó como resultado final displasia renal bilateral, ascitis urinaria secundaria a soluciones de continuidad de la vejiga, hipertrofia de los uréteres y obstrucción proximal de la uretra debido a Valvas Uretrales Posteriores.

Diagnóstico Patológico definitivo:

1. VALVAS URETRALES POSTERIORES.

2. Displasia Renal Bilateral secundaria.

3. Ascitis Urinaria. 


\section{SECUENCIA ECOGRAFICA DEL CASO CLINICO:}

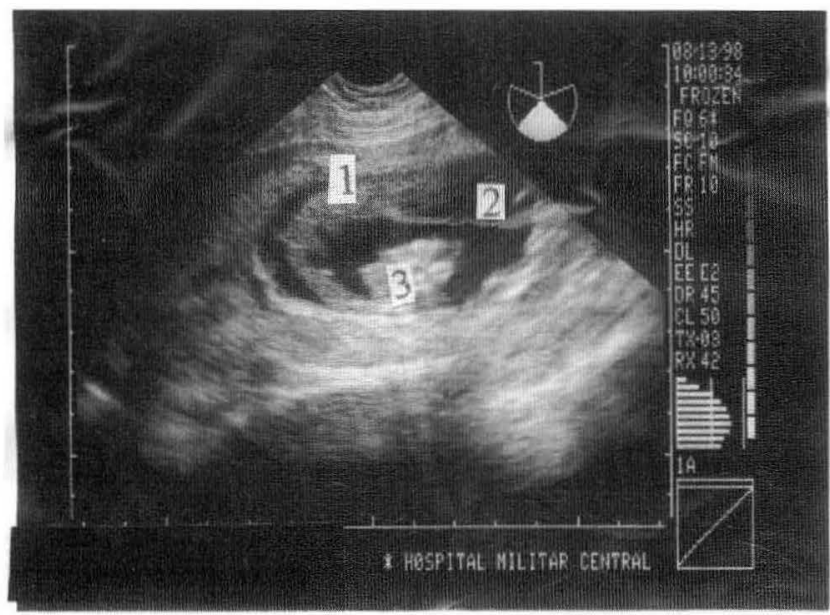

Foto 0003i01

1. Hígado. 2. Ascitis. 3. Intestino.

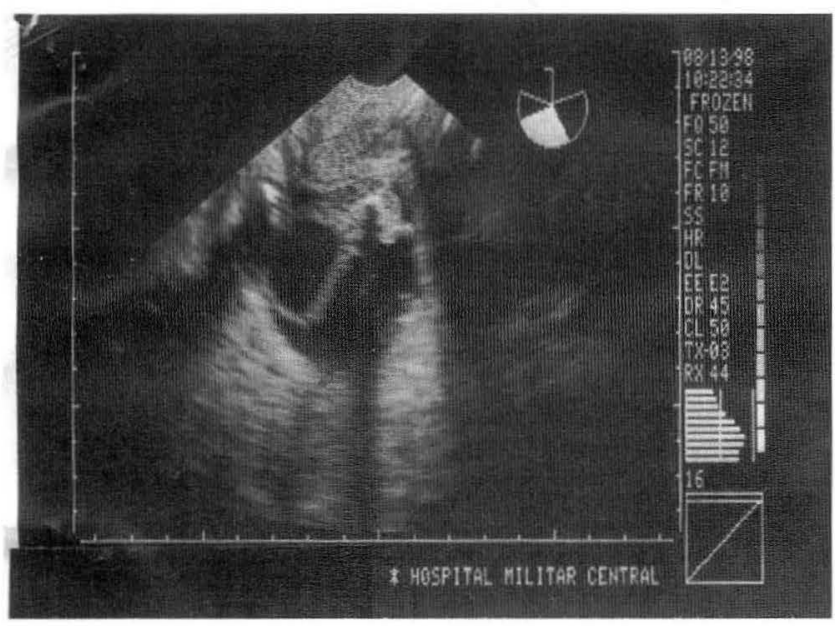

Foto $0003 \mathrm{i} 03$

1. Engrosamiento de la pared vesical

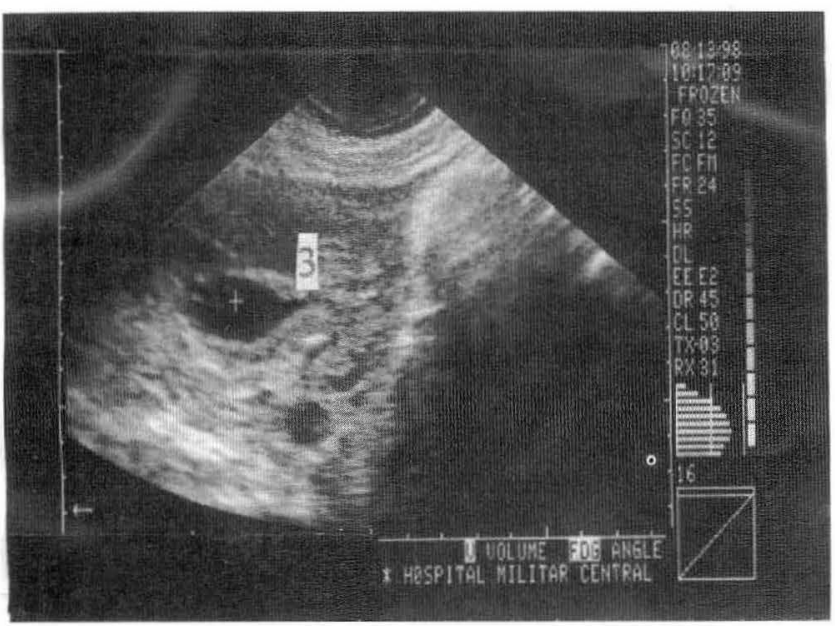

Foto $0003 \mathrm{i} 05$

3. Dilatación uretra proximal.

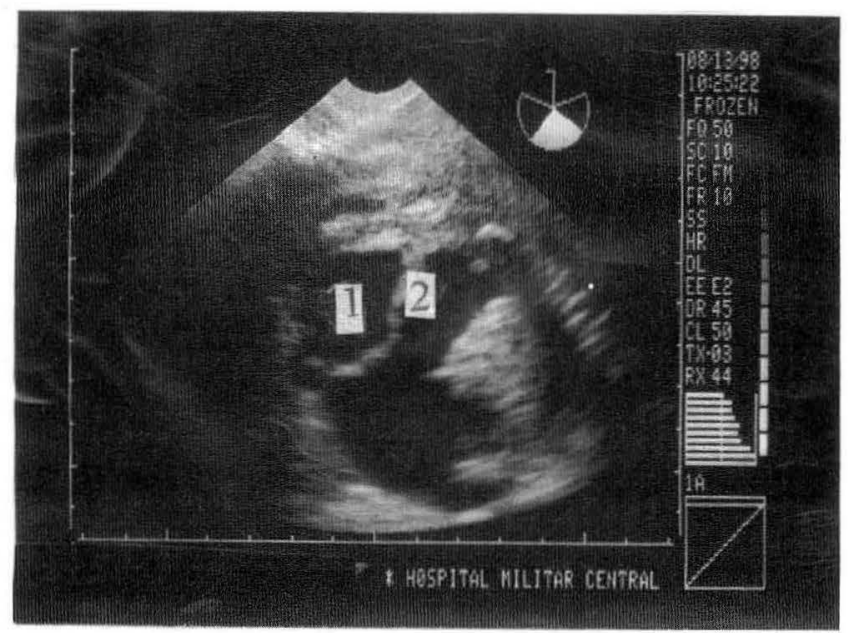

Foto $0003 \mathrm{i} 02$

1. Vejiga. 2. Pared vesical con soluciones de continuidad.

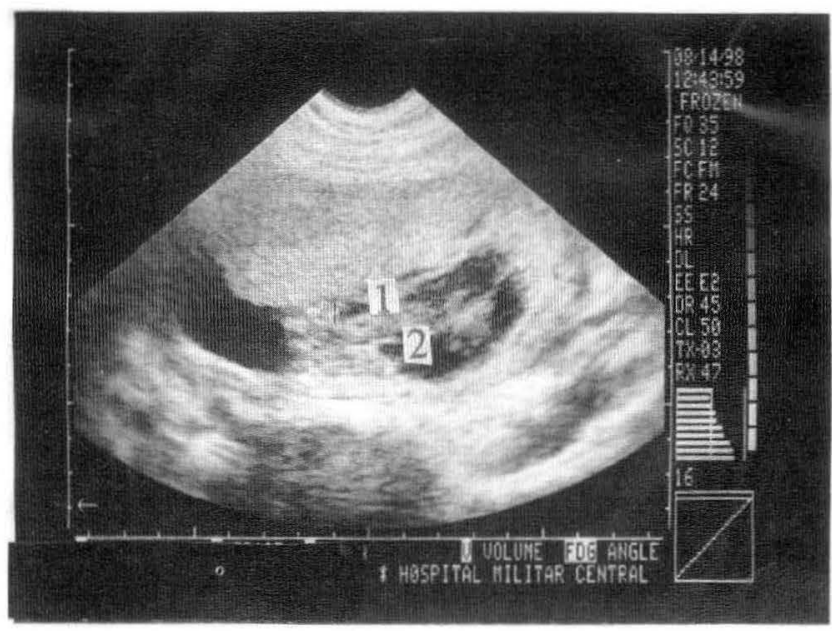

Foto $0003 i 04$

1. Dilatación unión uretero vesical derecha e izquierda.

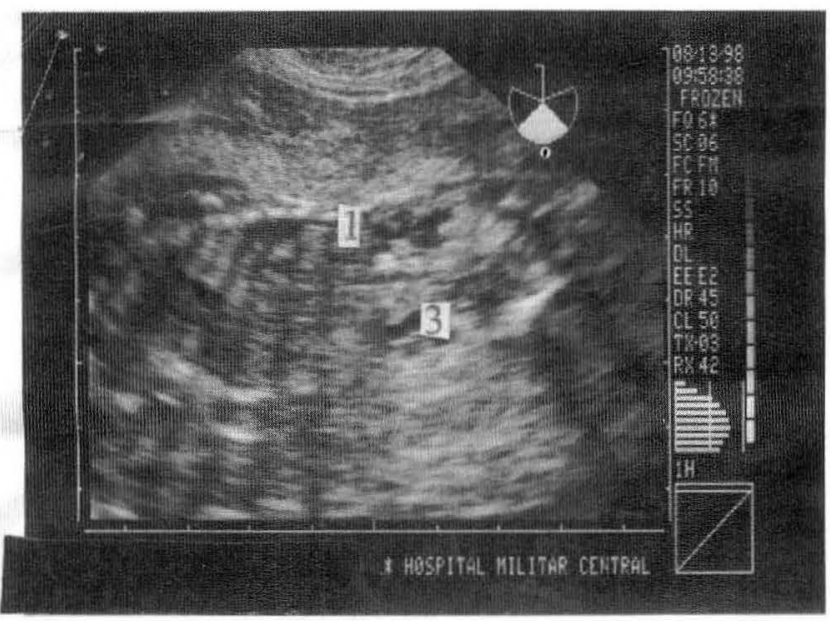

Foto $0003 i 06$

1. Pielectasia. 2. Comparativo al eje toráxico silueta renal grande. 3. Hiperecogenicidad del parénquima renal. 


\section{SECUENCIA DE HALLAZGOS MACROSCOPICOS:}

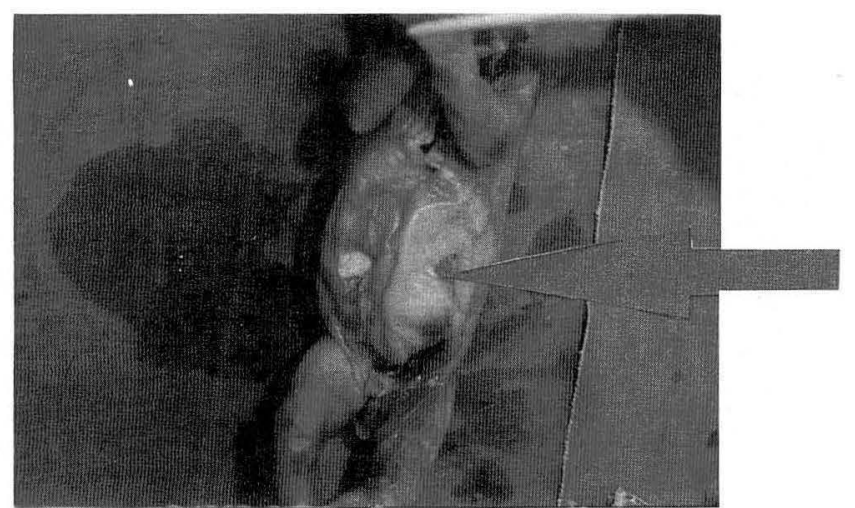

Foto 0003 i07

Feto masculino Pared abdominal distendida.

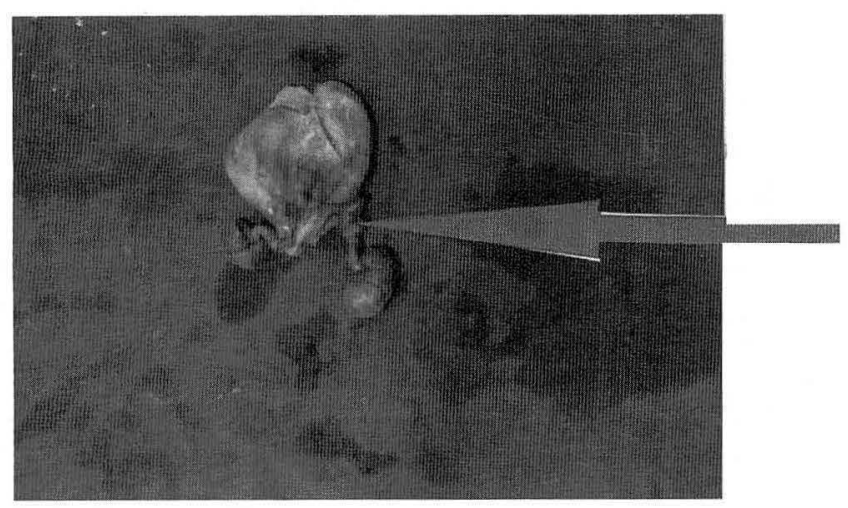

Foto 0003 i09

Hipertrofia ureteral

El interés de la presentación del caso clínico además de la detección de la patología es la correlación ecográfica y patológica de los hallazgos, la intervención intrauterina por la edad gestacional y la severidad del caso no se contempló de acuerdo al pronóstico.

\section{Uropatía obstructiva}

La incidencia de las anomalías fetales detectadas por ultrasonido es aproximadamente $0.4-0.65 \%$, de estas anomalías $40-50 \%$ son genitourinarias, considerando la Uropatía Fetal Obstructiva de aparición estimada de 1 en 500 imágenes de fetos. El promedio de edad gestacional para diagnóstico de estas anormalidades es de 17 semanas $(1,10)$.

La lesión obstructiva puede ser uni o bilateral y estar localizada en cualquier punto del tracto urinario. Las anormalidades mas comúnmente detectadas son la obstrucción de la unión ureteropélvica, valvas uretrales posteriores, atresia uretral, anomalías de la cloaca y enfermedades renales quísticas.

La historia natural de la uropatía obstructiva depende de la severidad y duración de la obstrucción y el resultado

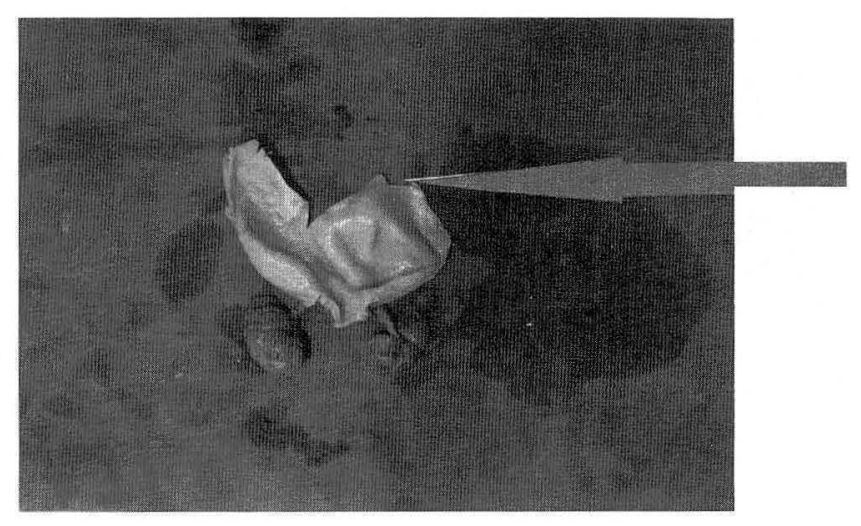

Foto $0003 \mathrm{i} 08$

Pared vesical con soluciones de continuidad. Dilatación vesical marcada.

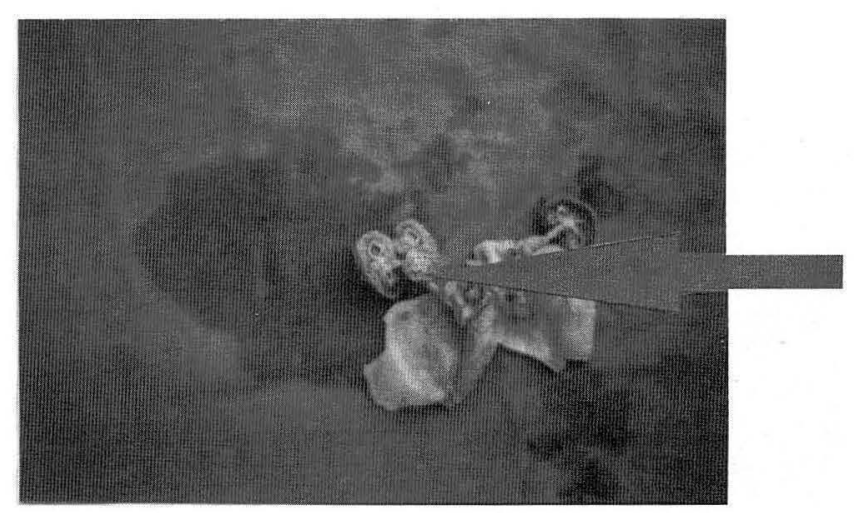

Foto $0003 \mathrm{i} 10$

Riñones fetales Hipertróficos Quistes renales.

se mide en términos de sobrevida postnatal, hay dos factores importantes que se deben tener en cuenta: la madurez pulmonar y la función renal. Un adecuado volumen de líquido amniótico es necesario para el desarrollo normal del pulmón fetal, la complicación más frecuente del oligohidramnios secundario a obstrucción del tracto urinario es la hipoplasia pulmonar y en casos severos la displasia renal final $(1,10)$.

\section{Embriología del tracto urinario (Figura N. 1)}

Desde las 6 semanas menstruales aparece el esbozo ureteral como una evaginación del conducto mesonéfrico del seno urogenital, pocos días después la parte caudal del seno denominada cloaca se angosta y se elonga para formar la uretra y el cuello de la vejiga; el resto de la vejiga deriva de la alantoides.

E1 esbozo ureteral crece y se ramifica por 15 generaciones dando origen al uréter, pelvis renal, cálices y los tubulos colectores, desempeña un papel importante en la inducción del nefrón, que aparecen por primera vez a las 10 semanas menstruales $(4,10)$. 
Desarrollo Embriológico de la Uretra y Vejiga (Figura N. 2)

En la cuarta y séptima semana del desarrollo, el tabique urorectal divide a la cloaca en el conducto anorectal y el seno urogenital primitivo. El conducto mesonéfrico o de Wolf entra hasta la pared anterior de la cloaca y retrocede hasta el nivel del verumontanum (elevación de la pared posterior de la uretra prostática y entrada del conducto seminal). La pared posterior de la uretra tiene dos repliegues normales llamados los repliegues uretrovaginales o plicatura colliculi, que son considerados remanentes de la migración cefálica del conducto de Wolf. En el seno urogenital primitivo se distinguen tres porciones:

1. La parte superior y más voluminosa es la vejiga.

2. Conducto estrecho (porción pelviana del seno urogenital) que en el varón da origen a las porciones prostática y membranosa de la uretra.

3. Seno urogenital definitivo.

El epitelio de la uretra masculina y femenina es de origen endodérmico y el tejido conectivo y muscular liso que la rodea deriva de la hoja esplácnica del mesodermo.

Hacia el final del tercer mes el epitelio de la uretra prostática comienza a proliferar y forma varias evaginaciones que se introducen en el mesénquima circundante.
La formación de orina comienza en el segundo trimestre y antes de las 16 semanas menstruales tiene una contribución escasa a la dinámica del líquido amniótico pero durante la segunda mitad del trimestre la micción produce la mayor parte del líquido amniótico.

\section{Aspectos ecográficos normales del tracto urinario}

Las variaciones de la posición fetal y la falta de contraste entre el riñón y el tejido circundante no permiten en ocasiones la identificación de ambos riñones, normalmente se visualizan en localización paraespinal a las 14 semanas mediante ecografía transabdominal y las 12 semanas por ecografía transvaginal. Deben estar definitivamente visualizados las 20 semanas menstruales.

Longitudinalmente los riñones muestran una forma elíptica y en el corte transversal tienen aspecto circular encontrándose adyacentes a los centros de osificación de la columna lumbar.

Los riñones normales tienen una longitud de 4 a 5 cuerpos vertebrales, la grasa retroperitoneal ecogénica rodea a los riñones, delinea sus perfiles con claridad tornándose evidente el seno central ecogénico. Las pirámides renales fetales hipoecoicas se disponen en hileras anteriores y posteriores con una configuración correspondiente a los cálices alrededor del seno central. La

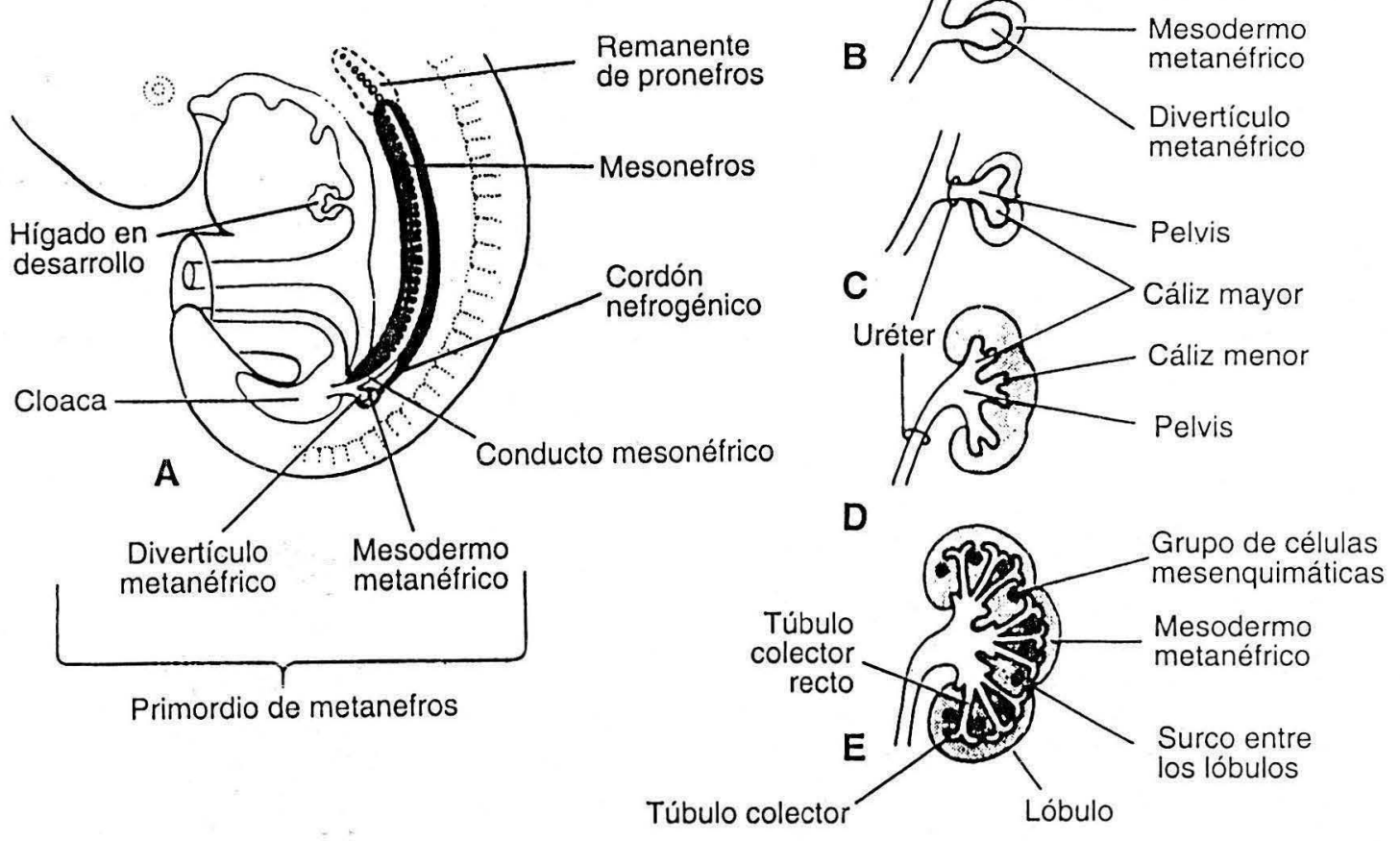

Figura 0003ill

DESARROLLO EMBRIOLOGICO DEL TRACTO URINARIO 

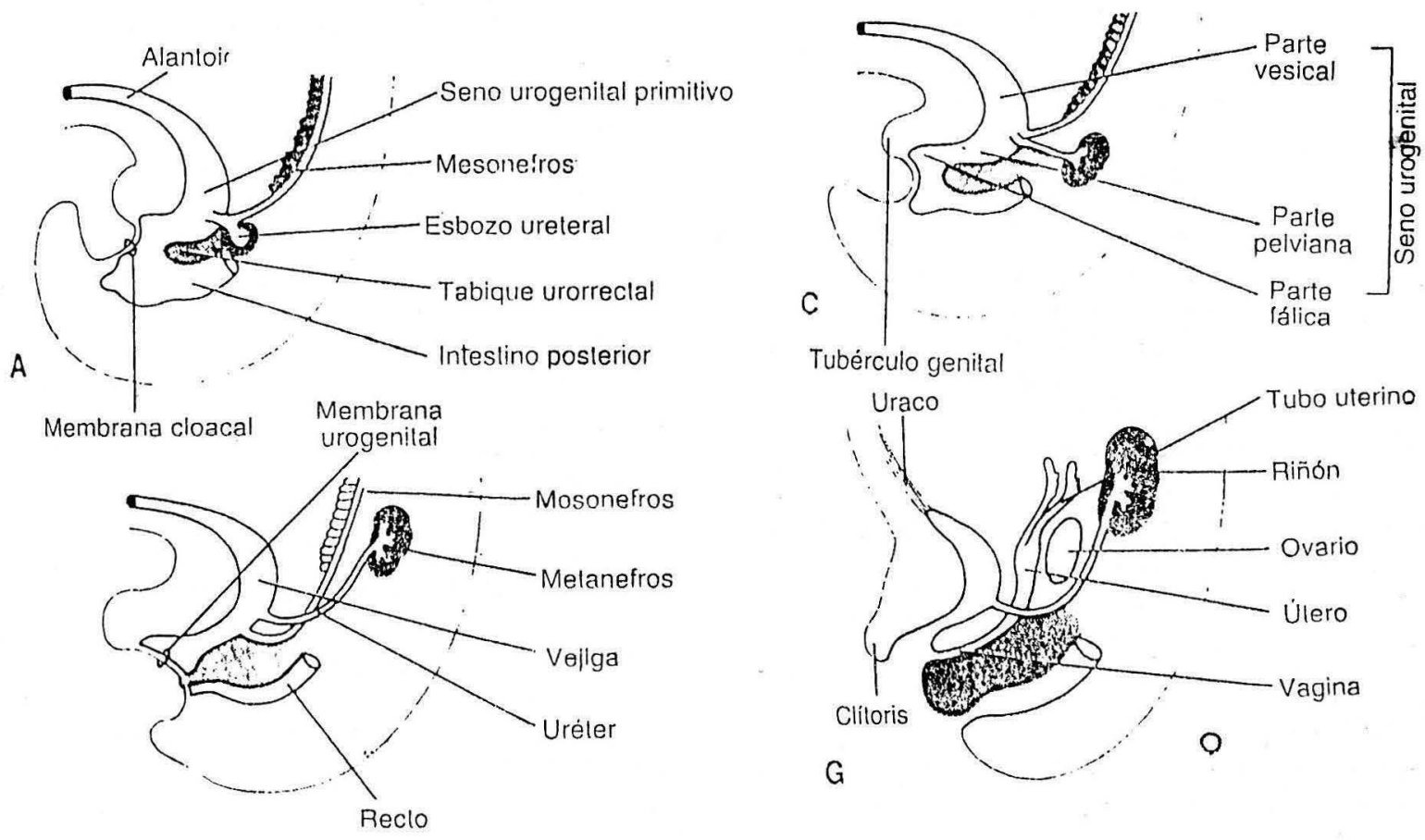

Figura 0003 i12

DESARROLLO EMBRIOLOGICO DE LA URETRA Y VEJIGA

intensidad hipoecoica relativa de las pirámides renales contrasta con la ecotextura de la corteza renal normal que se aproxima y en algunos casos supera la de los tejidos circundantes. Antes de la semana 24 de gestación la pelvis renal mide $4 \mathrm{~mm}$.

Los uréteres fetales no se visualizan, la vejiga normal tiene una pared delgada que no se visualiza y ocupa una posición anterior en la línea media dentro de la pelvis fetal, la uretra es difícil de detectar en los fetos masculinos en ocasiones se visualiza si el pene está flácido $(10,8,4)$.

\section{Valvas uretrales posteriores}

Las valvas uretrales posteriores son una malformación congénita de la uretra masculina, con origen embriológico heterogéneo que resulta de un desarrollo exagerado de los repliegues uretrovaginales con una anormal inserción de la parte final distal del conducto de Wolf, este repliegue patológico de mucosa origina las valvas circunferenciales obstructivas cuyo resultado es el reflujo vesicoureteral y la displasia renal final $(3-4,11)$.

Alrededor del $50 \%$ de los fetos afectados presentan oligohidramnios y sólo el $40 \%$ tiene pielocaliectasia o ureteroectasia asociada, la descompresión en forma espontánea a través de la ruptura del tracto urinario o la aparición de un urinoma perinéfrico se observa en un 10$20 \%$ de los casos severos.
Es una condición única de fetos masculinos y corresponde al $90 \%$ de las anomalías obstructivas encontradas en este sexo

La clasificación de las valvas uretrales posteriores fue propuesta por Young et al. en 1919 y está basada en las características anatómicas de las valvas. El más común es el TIPO I, que son pliegues distales del verumontanum que se insertan en la pared lateral de la uretra, es tratable en fetos humanos (12-13).

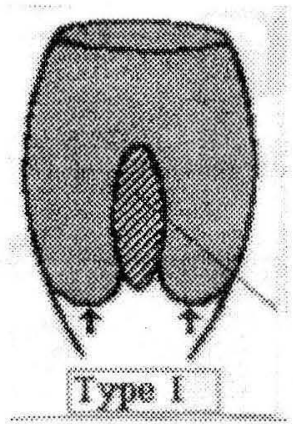

Figura 0003i13

VALVA URETRAL POSTERIOR TIPO I 
TIPO II: Es el más raro y consiste en pliegues de mucosa espirales a lo largo del eje longitudinal de la uretra, estos repliegues provienen del verumontanum, pasando muy próximos al cuello de la vejiga y probablemente nunca causen uropatía fetal obstructiva.

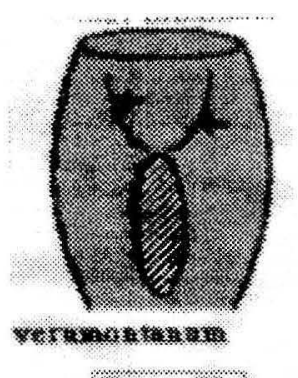

TYux II

Figura 0003i14

VALVA URETRAL POSTERIOR TIPO II

TIPO III: Es la menos común y consiste en repliegue transverso que ocluye la uretra en la porción distal del verumontanun (3).

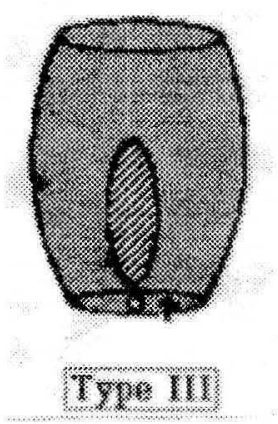

Figura 0003i15

VALVA URETRAL POSTERIOR TIPO III

\section{Diagnóstico}

La obstrucción del nivel uretral secundario a valvas posteriores tiene un amplio espectro de características ecográficas y los signos cardinales consisten en dilatación persistente de la vejiga y la porción proximal de la uretra, engrosamiento de la pared vesical mayor de $2 \mathrm{~mm}$, los uréteres están característicamente dilatados y tortuosos y en casos severos su entrada a la vejiga se observa (10-15).

El grado de dilatación de la pelvis renal es variable, en algunos casos de obstrucción severa y displasia renal la distensión de la pelvis está ausente, lo cual puede ser explicado por varias razones: 1. La disminución de la producción de orina por la displasia, 2. Ruptura de la vejiga o en otros puntos del tracto urinario. 3. Atresia pelviuréterica.

La consideración más importante con respecto al compromiso renal es la detección prenatal de la displasia. Esta puede ocurrir con riñones grandes o pequeños y el signo ecográfico patognomónico es la visualización de múltiples quistes e hiperecogenicidad del parénquima renal. A continuación índices diagnósticos de los diferentes criterios ecográficos para la identificación de displasia renal: (14). Tabla 1.

De los fetos con obstrucción en 10-20\% la vejiga se descomprime en forma espontánea a través de la ruptura del tracto urinario (ASCITIS) o la aparición del seudoquiste perinéfrico. El Oligohidramnios es un hallazgo invariable y está relacionado con la severidad y duración de la obstrucción, la presencia de un severo oligohidramnios es considerado de mal pronóstico (15-16).

\section{Diagnóstico diferencial}

Incluye otras uropatías obstructivas como:

- Obstrucción unión ureteropélvica

- Obstrucción unión ureterovesical

- Megaureter primario.

- Reflujo vesicoureteral masivo.

\section{Tratamiento}

La intervención prenatal está reservada a fetos cuyo diagnóstico se realiza después de la semana 24 con adecuada función renal y con inmadurez pulmonar que impide el nacimiento. El pronóstico es favorable pero está asociado a $5 \%$ de mortalidad y $25 \%$ progresan a falla renal crónica a pesar de la intervención.

El diagnóstico de la patología antes de la semana 24 tiene un pronóstico pobre, está asociado con $50 \%$ de muerte fetal y falla renal crónica posterior al nacimiento.

Tabla 1

CRITERIOS ECOGRAFICOS DE DISPLASIA RENAL

\begin{tabular}{|lcccc|}
\hline & Sensibilidad (\%) & Especificidad (\%) & PPV(\%) & VPN(\%) \\
\hline Quistes renales & 44 & 100 & 100 & 44 \\
Hiperecogenicidad del & & & & 57 \\
parénquima renal & 73 & 80 & 78 & 35 \\
Hidronefrosis & 41 & 73 & 78 & \\
\hline
\end{tabular}

Mahony. Filly Callen et al. Radiology 1984. 
En un feto con sospecha de uropatía obstructiva (MAYOR DE 24 SEM) debe realizarse una confirmación ecográfica para tratar de determinar con más precisión el origen o sitio de la patología, la apariencia del parénquima renal y por último la aspiración de orina fetal para cuantificación de los electrolitos y la osmolaridad $(1,4-5,10)$.

La evaluación de la función renal fetal debe realizarse por medio de la medición de electrolitos urinarios y factores proteínicos que son capaces de identificar falla y displasia renal.

Los valores descritos a continuación están asociados a buena función renal, adecuado pronóstico postnatal y ausencia de displasia renal, permiten un seguimiento posterior a la intervención intrauterina.

Sodio Urinario: menor de $100 \mathrm{mEq}$-dl.

Cloro: menor de $90 \mathrm{mEq}$-dl.

Osmolaridad: menor de 200 mos-L.

Beta 2 microglobulina: menor de $4 \mathrm{mg}$-dl.

El sodio urinario es el índice más usado para detectar disminución de la función renal con valores por encima $100 \mathrm{mmol} / \mathrm{L}$ y la concentración de calcio es el parámetro más sensible para la detección de displasia renal pero la especificidad es muy baja. Los niveles séricos fetales de creatinina, ácido úrico y electrolitos son iguales a los maternos, debido a su bajo peso molecular que ocasiona un rápido equilibrio transplacentario de tal forma que su determinación no tiene utilidad práctica.
La Beta 2 microglobulina tiene un peso molecular de $11.800 \mathrm{~d}$, los niveles no cambian con la edad gestacional, su paso transplacentario es improbable, por esta razón sus niveles no están alterados por los maternos, es filtrado por el glomerulo con una reabsorción del $99.9 \%$ por el tubulo renal proximal, que lo hace el parámetro más sensible para determinar la función renal fetal (5).

Una vez se determina una adecuada función renal y no hay ninguna malformación letal asociada, se hace seguimiento ecográfico del volumen del líquido amniótico, ante la presencia de oligohidramnios importante se procede a evaluar la madurez pulmonar, que en caso de ser negativa está indicado realizar intervención in útero, teniendo en cuenta la edad gestacional como parte fundamental del pronóstico. Para la realización del procedimiento se tienen en cuenta varias opciones:

1. Vesicocéntesis seriadas con guía sonográfica percutánea.

2. Vesicostomía fetal- ureterostomía fetal con cirugía fetal abierta.

3. Instrumentación Endoscópica con ablación de las valvas por medio del catéter transuretral $(1,10)$.

4. Derivación de orina fetal con Catéter percutáneo de Stend.

Todos los procedimientos mencionados tienen como objetivo la descompresión prenatal para detener los efectos adversos sobre el desarrollo renal y aparición de hipoplasia pulmonar, requieren alta experiencia.

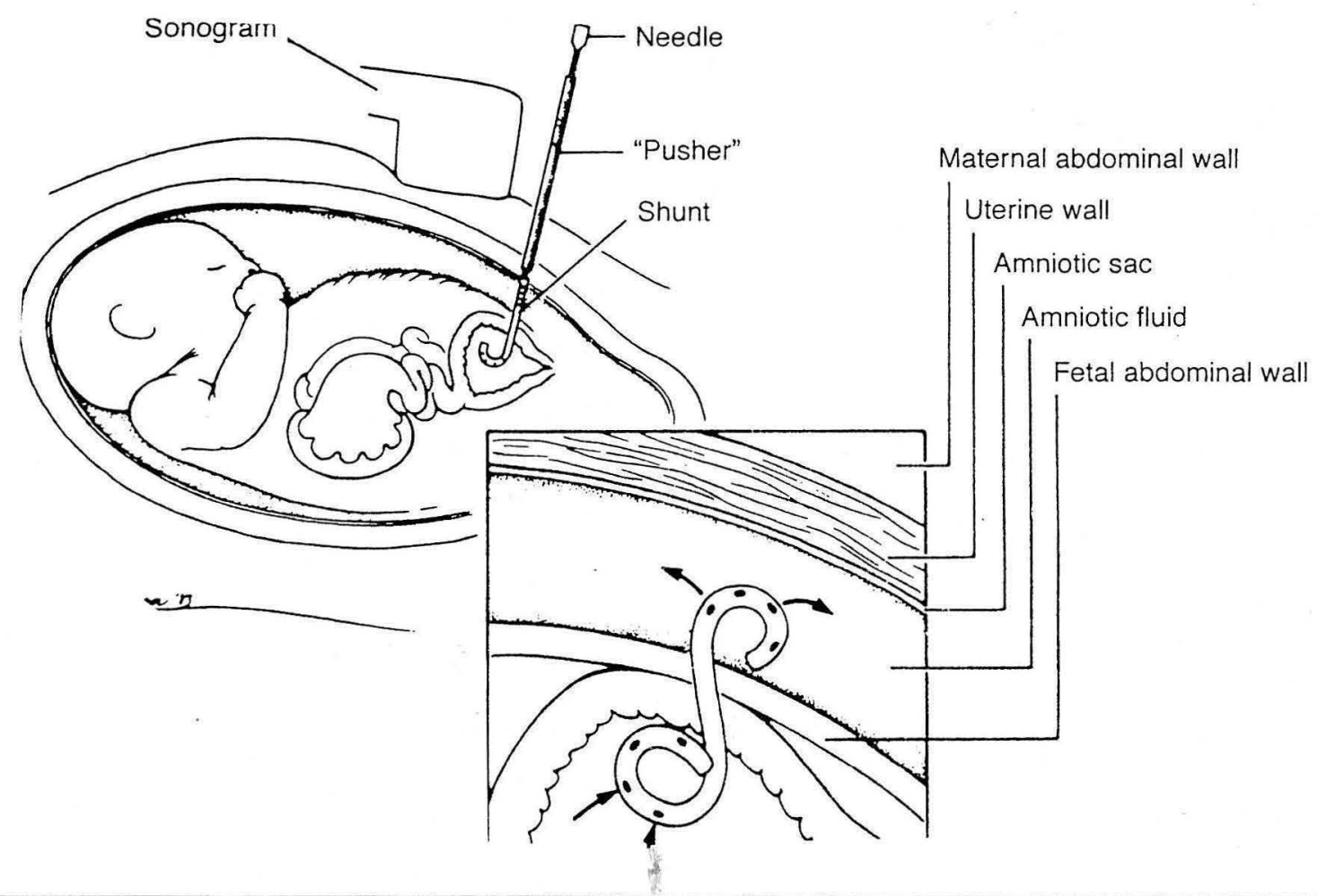


La vesicocéntesis seriada es un procedimiento que aumenta la morbilidad feto-materna, por el riesgo de infección intrauterina y otras complicaciones propias de la técnica, no se recomienda como tratamiento de la patología descrita $(1,4)$.

La exteriorización de la vejiga y el uréter por medio de cirugía fetal abierta es efectiva, pero las complicaciones son muy frecuentes.

El catéter percutáneo (Catéter de Harrison), de doble espiral, para derivación de la orina fetal al líquido amniótico, es una técnica que requiere sedación materna y fetal, su colocación se realiza bajo visión ecográfica utilizando aguja \# $12 \mathrm{G}$. Las complicaciones por la colocación son muy bajas y menos de $5 \%$ ocasionan daño fetal, la Amenaza de parto pretérmino es rara. Este procedimiento está aprobado por la FDA. A pesar de la adecuada colocación y funcionabilidad más de la mitad de ellos se obstruyen o se desplazan especialmente después de dos semanas; la obstrucción del catéter se debe a detritus celulares o sobrecrecimiento del tejido de granulación, por esta razón debe estar indicado en pacientes con edad gestacional cercana a la madurez pulmonar, se recomienda como tratamiento de la patología descrita con las limitaciones mencionadas (Fig. A).

La ablación transuretral de las valvas posteriores fetales permanece en la actualidad en experimentación se necesita alta experiencia, no se recomienda. Figura N. 6

\section{Pronóstico}

Los datos a largo plazo corresponden a casos diagnosticados después del nacimiento, pues cuando la patología es diagnosticada In Utero el pronóstico es malo. Los neonatos afectados se asocian con $35-50 \%$ de muertes. Las complicaciones más frecuentes son el neumomediastino y neumotórax relacionados con hipoplasia pulmonar además la falla renal crónica, anormalidades congénitas y complicaciones quirúrgicas relacionadas con la cirugía descompresiva.

La incidencia de la falla renal crónica en niños diagnosticados en los primeros tres meses de vida es de $39 \%$ y el seguimiento de la función renal debe realizarse con los niveles de creatinina durante el primer año, los niveles menores de $0.8^{\prime}$ están relacionados con buen pronóstico. TABLA N. 2.

\section{CRITERIOS PRONOSTICOS}

$\begin{array}{ll}\text { Buen pronóstico } & \text { Mal pronóstico }\end{array}$

L.A normal

Riñones normales

$\mathrm{Na}$ menor $100 \mathrm{mEq}-\mathrm{ml}$

$\mathrm{Cl}$ menor de $90 \mathrm{mEq}-\mathrm{ml}$

Osmolalidad menor $200 \mathrm{mOsm}$.

Diuresis mayor de $2 \mathrm{cc}-\mathrm{H}$

Beta 2 microglobulina menor $4 \mathrm{mg}$-dl.
Oligohidramnios severo

quistes renales

$\mathrm{Na}$ mayor de $100 \mathrm{mEq}-\mathrm{ml}$

$\mathrm{Cl}$ mayor $900 \mathrm{mEq}-\mathrm{ml}$

Osmolalidad mayor $90 \mathrm{mOsm}$.

Diuresis menor de $2 \mathrm{cc}-\mathrm{H}$

Glick Harrison et Al. J. Pediatrics Surg 20: 376. 1985.

\section{BIBLIOGRAFIA}

1. H. Tamiko, MD and Michel Harrison, MD. Fetal Urinary Tract Abnormalities. Urologic Clinics of North America 1998; 4(1): 63.

2. Michel D., Alessandro MD. Posterior Urethral Valves. 1998. Children Hospital IOWA.

3. Frak H., Miller, Jayc Lang MD. Posterior Urethral Valves. Brigham and Womens Hospital Departament Radiology. 1994.

4. Mahony BS., Callen PW. Fetal Urethral obstructive Us evaluation. Radiology 1985; 157-225.

5. Beatrice MG Jassa. Laura Trespide. Serum 82 Microglobulina in Fetuses with Urinary Tract Anomalies. Am J. Ginecology -Obst. 1997; part 1.

6. Mark Johnson MD. Timothy Bukowski, In Utero Surgical Treatment of Fetal Obstructive Uropathy. A. I Ginecology-Obstet. 1994; 170: $1770-1779$

7. Lane F., Donnelly, Victoria M.. Gylys. Unilateral Vesicoureteral reflux: association with protected renal function in patients with posterior urethral valves. A.J Roentgend, 1997; 168: 823-826.

8. Mark Paul Johnson, MD. Timothy Bukowski. In Utero surgical treatment of fetal obstructive uropathy: $A$ new comprehensive approach to identify appropriate candidates for vesicoamniotic shunt therapy. Am J Obstet Gynecol, 1994; 170: 1770-779.
9. Beatrice MG., Tassis, Laura Trespidi. Serum B2- microglobulina in fetus with urinary tract anomalies. A.J Obstetric Gynecol 1997; 176: 54-57.

10. Callen Peter, MD. Ecografia en obstetricia y ginecologia. Evaluación ecográfica del tracto genitourinario. Tercera edición. 1997.

11. Kelalis PP., King LR. Posterior Urethra. In Kelalis Clinical Pediatric Urology, 2 de. Philadelphia. Saunders. 1985; 527.

12. Glassberg $\mathrm{KL}$, Current issues regarding posterior urethral valves. Urol Clin North Am 1985; 12: 175.

13. Kurth KH., Alleman RJ., Schroder FH. Major and minor complication of posterior urethral valves. J Urol, 1981; 126: 517.

14. Mahony B., Callen PW., et al. Fetal Renal Displasia. Sonographic evaluation radiology. Radiology, 1984; 152: 148.

15. Adzick NS., Harrison MK.. Flake AW. et al: Urinary extravasation in the fetus with obstructive uropathy. J Pediatrics Surg 1985: 20:608.

16. Glazer GM., Filly RA., Callen PW. The varied Sonographic appearence of the urinary tract in the fetus and newborn with urethral obstruction. Radiology 1982; 144: 563. 